\title{
A new longitudinal study of the health and wellbeing of Australian children: how will it help?
}

Jan M Nicholson and Ann Sanson, on behalf of the LSAC Research Consortium

\begin{abstract}
The Longitudinal Study of Australian Children (LSAC) is a major research endeavour to assess emerging health and developmental concerns and their determinants in children. Previous longitudinal studies of children in Australia and New Zealand have contributed significantly, but have had limitations, which LSAC will attempt to address. A new generation of longitudinal studies is needed to enable transnational and historical comparisons. (MJA 2003; 178: 282-284)
\end{abstract}

IN MARCH 2002, the Commonwealth Department of Family and Community Services announced the commencement of the Longitudinal Study of Australian Children (LSAC). ${ }^{1}$ This study is being implemented by a large multidisciplinary research consortium led by the Australian Institute of Family Studies. It will track the health and development of two national, population-representative cohorts of children recruited in their first and fourth years of life. The study will assess a broad range of individual, family and environmental determinants of health and wellbeing, and will focus on identifying factors that influence good and poor life-course outcomes. The study aims to provide data that will inform the development of health, family and social policy and services within Australia (Box 1). LSAC represents a significant government investment $(\$ 20.2$ million over nine years) in longitudinal research on children, and it is timely to consider the extent to which it will address the shortcomings of past studies and add to our knowledge of children's health and development.

Longitudinal studies are essential to understand the causes of health problems and identify possible solutions. ${ }^{2}$ Using this type of study, Australian and New Zealand researchers have contributed significantly to our knowledge of health and development ${ }^{3-7}$ (Box 2). However, there are several reasons why Australia needs a new longitudinal study of children. Past studies typically recruited cohorts during the $1970 \mathrm{~s}$ and $1980 \mathrm{~s}^{8}$ and are therefore limited. First, the health profile of Australian children has changed significantly in recent decades. Emerging health concerns include increasing rates of atopic and chronic diseases and mental health problems, and unacceptably high levels of suicide, preventable injuries and harmful health behaviours during childhood and adolescence. ${ }^{9}$

Centre for Public Health Research, Queensland University of Technology, Kelvin Grove, QLD.

Jan M Nicholson, PhD, Senior Research Fellow.

Australian Institute of Family Studies, Melbourne, VIC.

Ann Sanson, PhD, Deputy Director.

Reprints will not be available from the authors. Correspondence: Dr Jan M Nicholson, Centre for Public Health Research, Queensland University of Technology, Victoria Park Rd, Kelvin Grove, QLD 4059.

j.nicholson@qut.edu.au
1: Questions to be addressed by the Longitudinal Study of Australian Children ${ }^{1}$

- How well are Australian children doing on key developmental outcomes?

- What are the pathway markers, early indicators, or constellation of behaviours that are related to different child outcomes?

- How are child outcomes interlinked with children's wider circumstances and environment?

- In what ways do features of children's environment (such as families, communities and institutions) affect their outcomes?

- What helps maintain an effective pathway, or change one that is not promising?

- How is a child's potential maximised to achieve positive outcomes for children, their families and society?

What role can government play in achieving these outcomes?

Second, the environments in which children are being raised have altered profoundly in the last 30 years. ${ }^{9,10}$ There have been changes to children's immediate environments (family, childcare, schools and neighbourhoods) and the broader sociopolitical climate (including widening social disparities). ${ }^{10}$ Past study findings may not be relevant to modern childhood environments. In addition, past cohorts were typically drawn from confined geographical locations, ${ }^{8}$ and data on health and social services and policies may not be more widely applicable.

Third, there have been considerable advances over the last 30 years in theory, measurement tools and analytic techniques. ${ }^{11}$ Current epidemiological models highlight the central role of individual genetic and pathobiological factors in the expression of poor health and the need to examine multiple levels of influence (Box 3). ${ }^{12}$ Past studies have been unable to explore these factors adequately, often lacking sufficient sample sizes or the appropriate measures to disentangle multilevel influences.

LSAC addresses a number of these limitations. Specifically, it will:

- measure a wide range of outcomes and determinants;

- recruit cohorts nationally from rural-regional and urban settings; and

- have a sufficient sample size to explore multiple determinants and the occurrence of relatively rare events. ${ }^{1}$

However, it is unrealistic to expect this study to address all research needs. For example, LSAC will not capture suffi- 


\section{2: Achievements of past Australian and New Zealand longitudinal studies of children's health and development}

\section{Study (starting date) \\ Australian Temperament Study $(1983)^{3}$ \\ Christchurch Health and Development Study $(1977)^{4}$}

Dunedin Multidisciplinary Health and Development Study $(1972)^{5}$

Port Pirie Cohort Study (1979)

Tasmanian Infant Health Study (1988) ${ }^{7}$

\section{Achievements}

Clarified the contribution of temperament, family and environmental factors to later life adjustment.

Contributed to child health, family and mental health policy, safety regulations for swimming pools and bicycle riding, and the development of early intervention programs for high risk mothers of infants.

Findings across a range of physical and psychosocial health areas contributed to the development of health interventions for substance use, safe driving and cycling practices.

Assessed the effects of environmental lead exposure and provided the impetus for changes in regulations relating to lead in petrol.

Assessed possible causes of sudden infant death syndrome, resulting in changed recommendations for infant sleeping positions, with documented reductions in infant deaths. cient children from minority groups to enable exploration of life-course pathways that may be unique to these populations. In addition, cost and methodological constraints are likely to result in the exclusion or under-representation of children from remote areas, and some forms of data collection will be too time-intensive or costly to use (eg, certain observational, biological or environmental measures). Also, LSAC will not involve the systematic provision of interventions. Given the growing evidence of the benefits to health that arise from prevention and early intervention, ${ }^{13}$ a strong case can be made for a coordinated program of longitudinal intervention trials to assess the impact of interventions delivered around key life-course transition times. ${ }^{14}$ Thus, studies of specific populations, studies addressing research questions that require costly data collection, and studies that involve the assessment of interventions could all add value. These could be designed in parallel with LSAC, or as studies nested within LSAC for creating efficiencies in research costs.

Australia is unique in geographical distribution of the population, family structures, ethnic diversity, social structures, policies and service provision. International research may have limited applicability in the Australian context. Nonetheless, it is important to consider Australian longitudinal research in an international context. Other Western nations are establishing new longitudinal studies, ${ }^{8}$ with European countries notable for coordinating studies that enable cross-country comparisons. ${ }^{15}$

LSAC may provide a foundation upon which other studies could be built to facilitate transnational comparisons and comparisons of changes to health pathways over time. Use of common design and measurement tools will facilitate these objectives. Longitudinal studies are expensive and demanding, not to be embarked upon lightly. ${ }^{2}$ Coordinated research efforts that strategically build upon the substantial national investment in LSAC may further enrich the evidence base for policy development and service provision to facilitate our nation's future health and wellbeing.

\section{Acknowledgements}

The Longitudinal Study of Australian Children (LSAC) is funded by the Commonwealth Department of Family and Community Services.

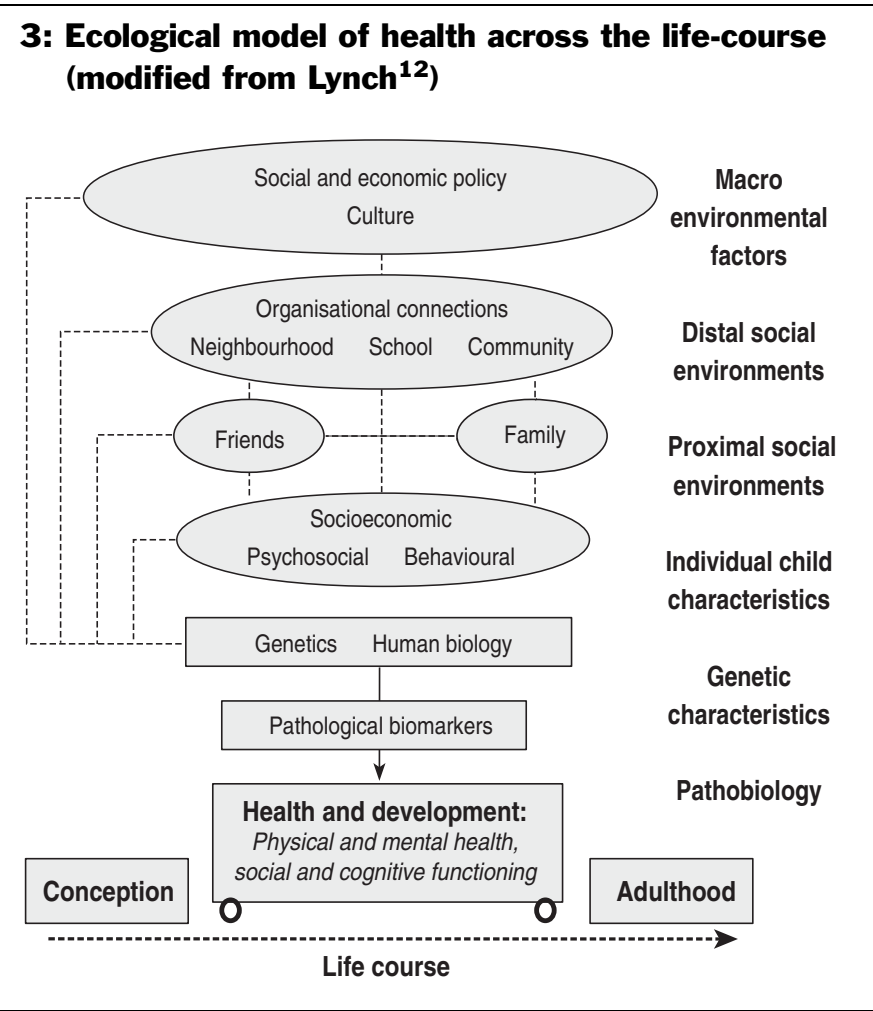

\section{Members of the LSAC (Longitudinal Study of Australian Children) Research Consortium}

John Ainley, Australian Centre for Educational Research; Donna Berthelsen, Queensland University of Technology; Michael Bittman, University of New South Wales; Dorothy Broom, Australian National University; Linda Harrison, Charles Sturt University; Bryan Rogers, Australian National University; Michael Sawyer, University of Adelaide; Sven Silburn, Curtin University; Lyndall Strazdins, Australian National University; Judy Ungerer, Macquarie University; Graham Vimpani, Newcastle University; Melissa Wake, Murdoch Children's Research Institute; Stephen Zubrick, TVW Telethon Institute for Child Health Research. 


\section{Competing interests}

$\mathrm{JMN}$ is a member of the Consortium Advisory Group and the Leader of the Design Team on Family Functioning. A S is the LSAC Project Director. Research for this article was supported by a grant from the Financial Markets Foundation for Children, Sydney, NSW.

\section{References}

1. Sanson A, Nicholson J, Ungerer J, et al. Introducing the Longitudinal Study of Australian Children. LSAC Discussion Paper Number 1. Melbourne: Australian Institute of Family Studies, 2002.

2. Rutter M. Beyond Iongitudinal data: causes, consequences, changes and continuities. J Consult Clin Psychol 1994; 62: 928-940.

3. Prior M, Sanson A, Smart D, Oberklaid F. Infancy to adolescence: Australian Temperament Project 1983-2000. Melbourne: Australian Institute of Family Studies, 2000

4. Fergusson DM, Horwood LJ, Shannon FT, Lawton JM. The Christchurch Child Development Study: a review of epidemiological findings. Paediatr Perinat Epidemiol 1989; 3: 278-303.

5. Silva PA, Stanton WR. Child to adult: the Dunedin Multidisciplinary Health and Development Study. Auckland: Oxford University Press, 1996.

6. Tong S, Baghurst PA, Sawyer MG, et al. Declining blood lead levels and changes in cognitive function during childhood: the Port Pirie Cohort Study. JAMA 1998: 280: 1915-1919.
7. Dwyer T, Ponsonby AL, Blizzard L, et al. The contribution of changes in the prevalence of prone sleeping position to the decline in sudden infant death syndrome in Tasmania. JAMA. 1995; 273: 783-789.

8. Nicholson JM, Sanson A, Rempel L, et al. Longitudinal studies of children and youth: implications for future studies. In: Sanson A, editor. Children's health and development: new research directions for Australia. Melbourne: Australian Institute of Family Studies, 2002: 38-62.

9. Stanley FJ. From Susser's causal paradigms to social justice in Australia? Int J Epidemiol 2002; 31: 40-45.

10. Keating DP, Hertzman C, editors. Developmental health and the wealth of nations: social, biological, and educational determinants. New York: Guildford Press, 1999.

11. West KK, Hauser RM, Scanlon TM. Longitudinal surveys of children. Washington: National Academy Press, 1998

12. Lynch JW. Social epidemiology: some observations on the past, present and future. Australas Epidemiol 2000; 7: 7-15

13. Karoly LA, Greenwood PW, Everingham SS, et al. Investing in our children. Santa Monica (CA): Rand, 1998

14. Loeber R, Farrington DP. Problems and solutions in longitudinal and experimental treatment studies of child psychopathology and delinquency. J Consult Clin Psychol 1994; 62: 887-900.

15. Golding J. Research protocol: European Longitudinal Study of Pregnancy \& Childhood (ELSPAC). Paediatr Perinat Epidemiol 1989; 3: 460-469.

(Received 24 Jun 2002, accepted 8 Oct 2002)

\section{OBITUARY}

\section{Vernon Richard Keep MRCS, LRCP, DA, MFARCS}

WHETHER IT WAS his unusual culinary flair or the way he discovered his profession, there was nothing conventional about Vernon Richard Keep.

Born in Harrow, UK, on 22 July 1927, Vernon had set his sights on being a naval engineer. Joining the Royal Navy in 1944, he spent four years as Chief Stoker aboard the Duke of York and various Australian warships, until pulmonary tuberculosis cut short his naval ambitions. Twelve months of being laid up in various sanatoria kindled Vernon's interest in bacteriology and sowed the seeds of his medical career. On release, he was advised that he would need a medical degree if he wanted to be a bacteriologist.

Upon matriculating, Vernon enrolled in Middlesex Hospital Medical School, London, in 1949. Recurring TB meant a protracted study period, and he graduated in 1957. After various training posts in medicine, surgery, casualty and urology, he settled on the emerging field of anaesthesia. Training included thoracic surgical anaesthesia at the Brook Hospital, London, and plastic and faciomaxillary surgical anaesthesia at the Queen Victoria Hospital, East Grinstead. His pioneering work included opening one of the world's first intensive care units at Middlesex Hospital.

Disenchanted with the British National Health Service, Vernon migrated with his young family to Perth, Western
Australia, in 1962. On arrival, he briefly held the position of Staff Anaesthetist at Royal Perth Hospital before being appointed the first Director of Anaesthesia at Fremantle Hospital. It was during his tenure at Fremantle that he formulated the Civil Disaster Plan for the busy port city.

Improvements in anaesthetics led him to experiment with the concept of rapid-recovery day surgery, and he opened the first custom-designed clinic, Kaleeya House, in 1968. Interest was so great that, in 1974, the first purpose-built outpatient hospital in Australia, Kaleeya Hospital, was opened in East Fremantle. As Chairman of the Board, he oversaw the finer details, such as the selection of lime-green paint and psychedelic bed linen.

In 1980, Vernon and his wife Lyn retired to their farm, "Lanark Park", in Wokalup, for some "peace and quiet". But retirement proved short-lived, and he took up various medical positions around the Harvey area until ill health forced him into hospital in October 2002.

From his ward on the ninth floor of Fremantle Hospital, Vernon was reassured to see his old surgery, Kaleeya House, and the Medical Library at Fremantle Hospital, which he had founded nearly 40 years previously. He died on 4 January 2003 from pneumonia complicated by TB damage and emphysema. He is survived by three sons and three grandchildren.

Matthew J Keep 